\title{
Seroprevalence Study on Human Toxocariasis (T. canis) with Relation to Religion Using ELISA Technique: A Case Study of Six Government Hospitals Adamawa State, Nigeria
}

\author{
Terry Thomas $^{1 *} \quad$ Qadeer Mohammed ${ }^{2}$ \\ 1.Department of Biomedical Sciences and Technology, Federal Polytechnic P.M.B 35, Mubi, Adamawa State, \\ Nigeria \\ 2.Department of Zoology, School of Life Sciences, Modibbo Adama University of Technology, Yola, Adamawa \\ State, Nigeria
}

\begin{abstract}
Seroprevalence study on human Toxocariasis (T.canis) Antibody titre using ELISA Technique was conducted amongst the two major religions (Christians and Moslems) in Six Government Hospitals of Adamawa State Nigeria, between the months of January to June 2018. Five hundred and sixty four (564) samples were collected using non randomised sampling technique. Statistical analyses were carried out using Statistix 9.1 and the results obtained from the study revealed an overall Seroprevalence rate of $46.82 \%$. Seroprevalence results indicated that $167(29.61 \%)$ Christians and 97(17.21\%) Moslems were positive showing a negative correlation (-0.0332) and was statistically non-significant $\mathrm{P}=(0.4315)$. In conclusion the study showed that there is a very high Seroprevalence of Toxocara canis Antibody titre amongst the different religions in the studied population. Therefore it is recommended that Anti-Toxocara Antibody screening be included into routine medical diagnosis in government hospitals and also in private medical outfits. It is also recommended that further studies on molecular diagnosis be carried out to ascertain the gene markers responsible for the pathology caused to the host by (T.canis).
\end{abstract}

Keywords: Antibody, Seroprevalence, Religion, Tribe, Adamawa, pork, Toxocara canis and Seropositivity DOI: $10.7176 / \mathrm{JBAH} / 9-10-07$

Publication date:May $31^{\text {st }} 2019$

\section{Introduction}

Toxocariasis is a neglected infection that has a worldwide distribution. T.canis is the most relevant agent due to its frequent occurrence in humans. Over the years, this disease has drawn much attention because of its surprisingly high prevalence (Anna et al,. 2018). Parasite eggs are commonly found in soil and canine fur, dirty hands, consumption of vegetables contaminated with embryonated eggs or consumption of embryonated egg in paratenic hosts such as chicken, beef from cattle, pork and other small animals. Previous studies have reported varying seroprevalence rates amongst different cultures and religions in various locations around the world which agree with the findings in this study. The overall seroprevalence rate in this study amongst the two major religions sampled in the study area was $46.82 \%$, this result agrees with similar works earlier reported among different cultures and religions by Alonso et al,. (2000), who reported a positivity of 37.9\% in Argentina; Epinoza et al,. (2008) reported 32.4\% positivity in Peru and Brazil. Similarly Ajayi et al,. (2014) reported 29.8\% positivity in Jos, Nigeria. Other findings show 1.6\% in Japan, 2.4\% in Denmark, 6.3\% in Australia, $7 \%$ in Sweden, $14 \%$ in USA and $19.6 \%$ in Malaysia (Guangxu et al,. 2018).

\section{Materials and Methods \\ Study Area}

Adamawa State is located at the North Eastern part of Nigeria. It lies between latitude $7^{0}$ and $11^{0} \mathrm{~N}$ of the equator and between longitude $11^{0}$ and $14{ }^{0} \mathrm{E}$ of the Greenwich meridian. It shares boundary with Taraba State in the South and West, Gombe State in the Northwest and Borno to the North. Adamawa State has an international boundary with the Cameroon Republic along the Eastern border. The State covers a land area of about 38,741km with a population of about 2,102,053 people according to the 1991 census. Christianity and Islam are the religions in the State though the practice of traditional religion occurs among some tribes in the State. Adamawa State is divided into 21 Local Government Areas as indicated in Fig 1 (Adebayo and Tukur 1999). 


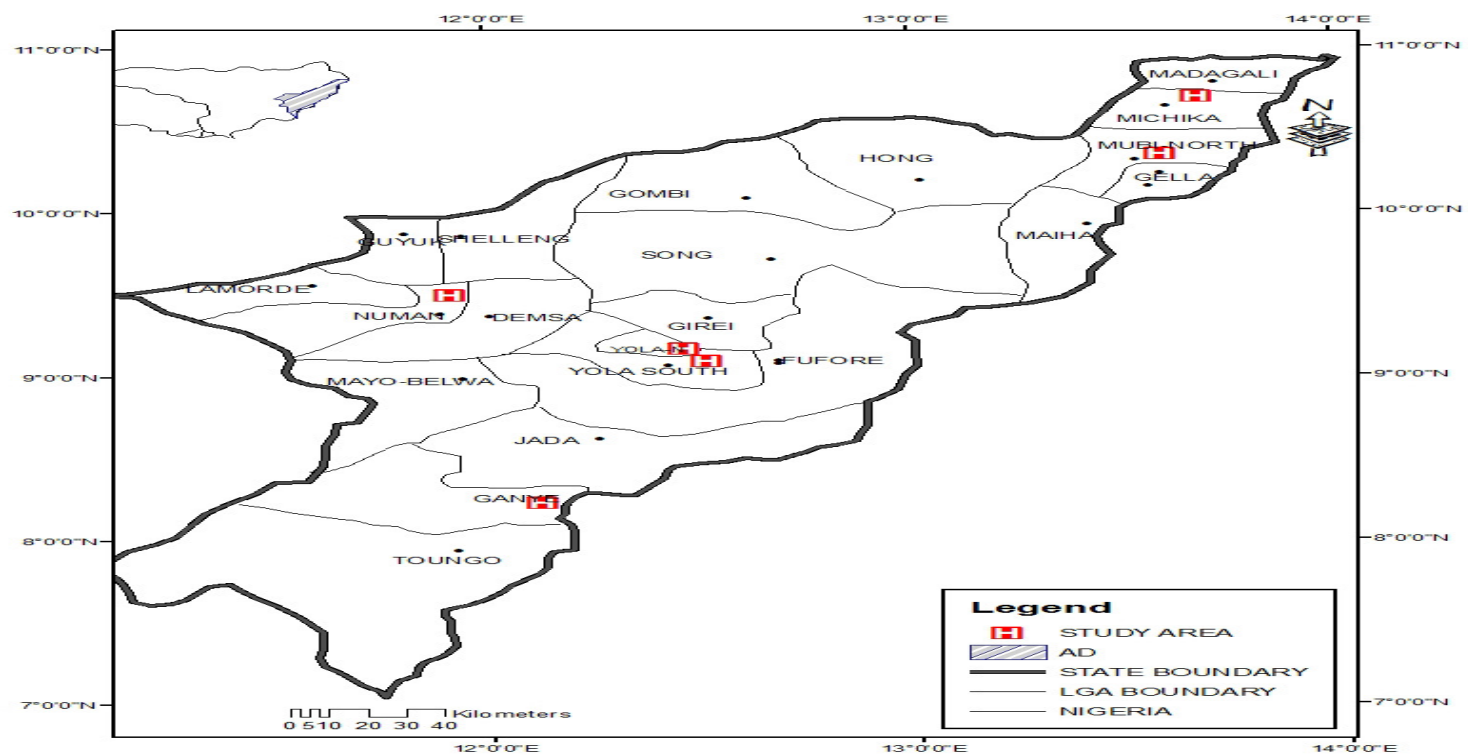

Fig1. Map of Adamawa State Showing Study Sites Data collection

\section{Data Collection}

Data were collected through a designed collection form to capture information on religion and through blood samples collected from patients' refereed to the Haematology Laboratories of the various Hospitals in the study area.

\section{Study design and Sample collection}

One hundred (100) blood samples each were collected from each of the six Hospitals in the study area. A non randomised sampling technique were used, where whole blood was collected through the venous puncture with the aid of Sterile syringe and approximately $5 \mathrm{ml}$ of whole blood was obtained and emptied into plain gel vaccontainer tubes pre-labelled with information on Age, Sex, Location, Socioeconomic status and religion. The blood samples were than centrifuged to separate serum from the red cells, the serums were then used for analysis.

\section{Laboratory Analysis}

Enzyme Link Immunoabsorbent Assay (ELISA) Toxocara canis Antigen Kit product №.8206-35 supplied by Diagnosis Automation/Cortez Diagnostics Inc. Woodland Hills California USA was used for Analysis which were carried out in the Haematology Laboratory of the Federal Medical Centre Yola, Adamawa State Nigeria.

\section{Statistical analysis:}

Statistix 9.1 (2012) Statistical package for scientist and engineers, USA, was used for statistical analysis.

\section{Result and Discussions}

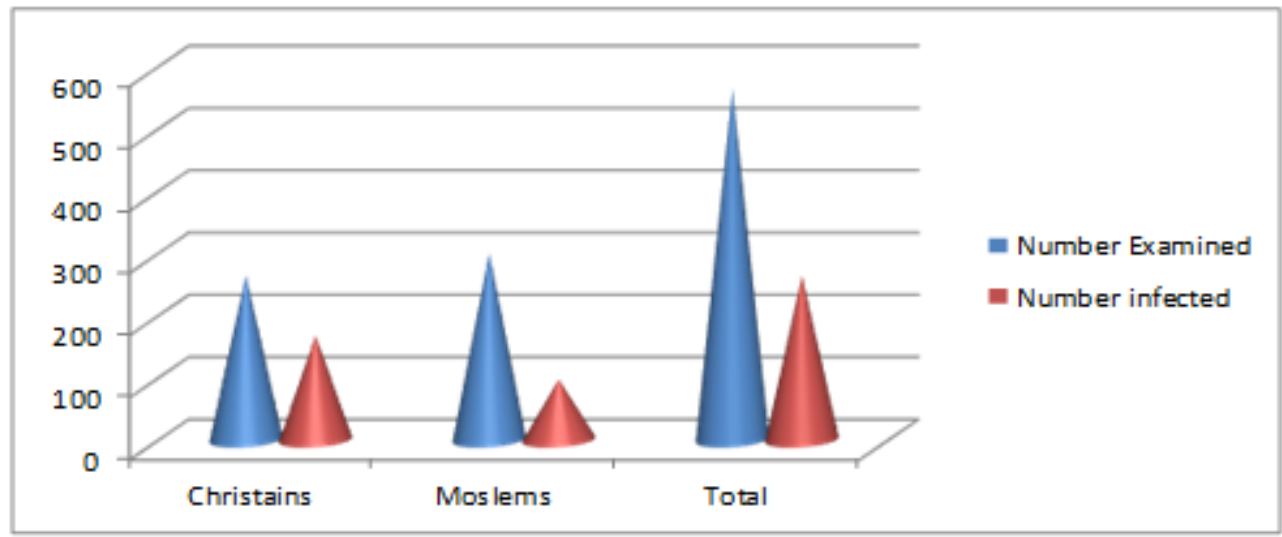

Figure 2. Seroprevalence of Anti-Toxocara Antibody titre base on Religion

Prevalence rate based on Religion figure 2 revealed that Christians accounted for $167(29.61 \%)$ while 
Moslems had 97(17.21\%) infections rates. Moslems sampled in the study area include the Fulani's, Hausa and order tribes who are cattle rearers and have the habit of keeping dogs that assist them in shepherding their herds during grazing and sometimes use them for hunting, exposing them to the Parasite (T.canis). Though accounting for lower rates of infection as compared can be justified by their religious practices where contact with dogs is prohibited (Berenji et al,.2016). Tina et al,. (2016) reported that Islam forbids any contact with dog or any other material which has been in any way exposed to the animal itself or its urine and faeces. Furthermore, in Islamic countries, dogs are avoided for religious reasons, but cats are favoured as pets, the seroprevalence of human Toxocariasis can be considerable (Smith and Noordin 2006). Thus the potential roles of Toxocariasis in humans should not be ignored or underestimated in the Islamic world (Fisher, 2003).

Christians accounting for 167(29.61\%) can be attributed to their keeping of dogs, as the religion does not prohibit the practice. In Adamawa State, some Christian dominated areas in the State are known to eat dog meat. This can be attributed to the high rate amongst the Christians as previous report have indicated that there is a significant relationship between having a dog and Toxocariasis (Nourian et al,. 2009; Berenji et al. 2016). Contact with dogs has been shown in several studies as an important risk factor for Toxocariasis. Damain et al. (2007) reported in a cross- sectional study amongst 34 families in Amazonas State in Brazil, individuals who had contact with adult dogs, $60 \%$ were positive, and those who had contact with puppies $66.6 \%$ demonstrating the association between contact with dogs and the presence of Toxocara Antibody. Results obtained in this work also agrees with earlier report by Chiodo et al,. (2006) who after evaluating 100 individuals for IgG anti Toxocara, 23\% were positive and all had contact with dogs. However pet owners might not be exposed to the disease more frequently than non-pet owners, especially if they take good care of their pets (Traversa et al. 2014; Gabrielli et al. 2017). Some studies refer that soil contamination is not the only effective route in human Toxocariasis and eggs of Toxocara spp. can be sprouted in fur and direct contact between humans and dogs as Aydenizoz-Ozkayhan et al,. 2008 collected 51 fur samples and observed that $21.56 \%$ of dogs had eggs on their fur. Similar studies carried out by Roddie et al 2008 and Overgaauw et al,. 2009 in the Northlands, found 12.2\% of Toxocara eggs in dog fur; moreover, many of the owners allow their dogs to climb and sleep in their beds, and only few wash their hands after contact with pets; therefore this close physical contact with pets and their owners possibly increase the risk of transmission of Toxocara spp. and point to the need for greater attention to the potential risk to which humans are exposed. Other reasons that probably accounted for Christians having a higher rate could be attributed to the role of their women in farming activities, which exposes them to contaminated soil environment which has been known to be a risk factor in $T$. canis infection. The practice of women engaging in farming activities is common amongst the Christians'. The practice of clearing the animal waste mostly done by the women also exposes the to the risk of cross contamination with the causative parasite thereby increasing the chance of contracting the infection. Religion in this study showed a negative correlation (r-0.0332) to T. canis infection and is statistically non- significant $(\mathrm{P}=0.4315)$.

\section{Conclusion}

In conclusion the study showed that there is a high Seroprevalence rate of Toxocara canis Antibody titre amongst the two major Religions sampled in the studied population

\section{Recommendations}

Therefore it is recommended that Anti-Toxocara Antibody screening be included in the routine medical diagnosis. It is also recommended that further studies on molecular diagnosis be carried out to ascertain the gene markers responsible for the pathology caused to the host by T.canis

\section{Acknowledgement.}

Authors wish to acknowledge the contributions of the Management, Laboratory Scientist of the Federal Medical Centre Yola, Adamawa State Nigeria., Adamawa State Ministry of Health and Adamawa State Hospital Management Board.

\section{References}

Adebayo, A .A and Tukur, A.I. (1999). Adamawa State in map $1^{\text {st }}$ Edition Paraclete publishers Yola. 1-3

Ajayi, O.O, Duhulinska, D.D., Agwale, M. and Njoku, M (2000). Frequency of Human Toxocariosis in Jos Plateau State, Nigeria. Mem institute Oswaldo Cruz 95(2):147-149

Alonso, J.M., Bojanich, M.V.L., Chamora, M., Gorodher, J.O., (2000). Toxocara seroprevalence in children from Subtropical City in Argentina. Review of Institute of Medicine in Tropics, 42, 235-237.

Anna, K., Kacper, T., Eizbieta, O and Artuk, . (2018). Toxocariasis in Children: Poor hygiene habits and contact with dogs is related to longer treatment: Parasitology Research http://doi.org/10.1007/500436-018-5833-7.

Aydenizöz-Özkayhan, M. Yağci, B. B and Erat, S. (2008). The investigation of Toxocara canis eggs in coats of different dog breeds as a potential transmission route in human Toxocariosis. Veterinary Parasitology. 152: 
94-100

Berenji.(2016). Seroepidiomological Study of Toxocariasis in the owners of dogs. Iran Journal of Parasitology, 11: $265-268$

Chiodo, P., Basualdo, J., Ciamela,L., Pezzani, B., Apezteguia, M., Minvielle, M. (2006). Related factors to human Toxocariasis in rural community of Argentina. Mem institute Oswaldo Cruz, 101: 397-400

Damian, M. M., Martins, M., Sardinha, J.F., Souza, L.O., Chaves, A and Tavares, M. (2007). Frequencia de anticorpo anti-Toxocara canis Comunidade do Rio Uatuma. no Estado do Amazons. Reviews of Society of Brasil Medicine in Tropic, 40: 661-664

Espinoza, Y.A., Huapaya, P.H., Roldan, W.H., Jimennez, S., Arce,Z., Lopez, E. (2008). Clinical and Serological evidence of Toxocara infection in School Children from Morrope ditrict, Lambayeque, Peru. Review of Institute of Medicine in Tropics , 50:105-105

Fisher, M. (2003). Toxocara cati: an underestimated zoonotic agent. Trends Parasitology, 19: 167-170

Gabrielli, S., Tasic-Otasevic, S., Ignjatovic, A., Trenkic-Bozinovic., Momcilovic, S., Cancrini, G. (2017). Seroprevalence and risk factors for Toxocara canis infection in Serbia during 2015. Foodborne Pathologic Diseases, 14: 43-49

Guangxu, M., Celia, V.H., Tao,W., Andreas ,H., Chia-Kwung, F., Rick, M.M.,Peter, J.H., and Robin, B.G. (2018) .Human Toxocariasis. The Lancet, 18: 16-17

Overgaauw, P.A.; Van Zutphen, L.; Hoek, D.; Yaya, F.O.; Roelfsema, J. et al.(2009). Zoonotic parasites in fecal samples and fur from dogs and cats in The Netherlands. Veterinary Parasitology.163, (1-2), 115-122

Nourian, A.A., Amiri, M.M Ataenan, A Haniloo,S.N., Mosavinaab, and Baali, H. (2008). Seroepidiomological study for Toxocara among children in Annan-Northwest of Iran. Pakistan Journal of Biological Sciences. 11 (14): 1844-1847

Roddie, G., Stafford P. Holland.C and Wolfe, A. (2008). Contamination of dog hair with eggs of Toxocara canis. Veterinary Parasitology. 152: 85-93

Smith, R and Noordin.(2006). Diagnostic limitations and future trends in the serodiagnosis of human Toxocariasis. Holland, C.V. and Smith, H.V. (Eds.), Toxocara: The Enigmatic Parasite, CABI Publishing, CAB International, Wallingford, Oxfordshire, UK: 89-112

Tina, M., Mahani-Oskouei, M., Fallah, E., Safiayan, A and Mahami-Oskouei, L.(2016). Latent an Asymptomatic Toxocara Infection among young population in Northwest Iran: The necessity of informing people as a potential Health Risk. Scientifica. 1-5

Traversa, D. (2012). Pet roundworms and hookworms: a continuing need for global warming. Parasite Vectors 5:91-100 